\title{
STUDI KUALITAS AIR DAN KEANEKARAGAMAN JENIS IKAN DI SUAKA PERIKANAN(RESERVAT) LUBUK MANIK KECAMATAN RANTAU PANDAN KABUPATEN BUNGO PROVINSI JAMBI
}

\author{
Surya Patri ${ }^{1}$, Rini Hertati, ${ }^{2}$, Djunaidi, ${ }^{3}$ \\ 1 Mahasiswa Program Studi Pemanfaatan Sumberdaya Perikanan \\ 2 dan 3 Pengajar Pada Program Studi Pemanfaatan Sumberdaya Perikanan \\ Universitas Muara Bungo
}

\begin{abstract}
ABSTRAK
Suaka Perikanan (Reservat) Lubuk Manik adalah salah satu suaka perikanan tertua di Propinsi Jambi yang berada di Kababupaten Bungo tepatnya di Kecamatan Rantau Pandan yang juga merupakan bagian dari hulu Sungai Batang Bungo dengan luas 4.500 $\mathrm{M}^{2}$. Suaka perikanan ini disahkan pada tahun 1990, diresmikan oleh Pemerintah Pusat pada tahun 1994 dan kembali dikukuhkan zonasinya oleh Pemerintah Kabupaten Bungo pada tahun 2006 (Dinas Peternakan dan Perikanan Bungo, 2006).

Tujuan penelitian ini adalah untuk mengetahui kualitas air dan keanekaragaman jenis ikan suaka perikanan (Reservart) Lubuk Manik di Kecamatan Rantau Pandan Kabupaten Bungo. Metode penelitian yang digunakan Metode Deskriptif kuantitatif, yaitu untuk memberikan gambaran dan penjelasan secara sistematis, faktual, dan akurat mengenai fakta-fakta dan gejala yang ada di lokasi penelitian.

Hasil pengukuran karakteristik kualitas air (fisika dan kimia) yang diperoleh dibandingkan dengan standar baku mutu air berdasarkan Peraturan Pemerintah Nomor 82 Tahun 2001 tentang Pengelolaan Kualitas Air dan Pengendalian Pencemaran Air sesuai dengan peruntukkan kegiatan perikanan dalam klasifikasi Kelas III.

Berdasarkan Dari Hasil Penelitian Kondisi kualitas perairan Suaka Perikanan Lubuk Manik Rantau Pandan ditinjau dari parameter fisika dan kimia perairan masih dalam kisaran normal dan tidak ada yang melampaui ambang batas Baku Mutu Air Kelas III peruntukan kegiatan perikanan yang telah tertuang dalam PP RI No. 82 Tahun 20011.

Berdasarkan hasil perhitungan nilai indeks keanekaragaman dimana indeks tertinggi ditemui pada Stasiun II dengan nilai indeks 1.6565 , terdapat 18 spesies jenis ikan yang terdiri dari 57 individu ikan yang tertangkap saat penelitian. Stasiun I dengan nilai indeks 1.5254, 17 spesies jenis ikan yang terdiri dari 47 individu ikan yang tertangkap saat penelitian, dan Stasiun III dengan nilai indeks 1.1334, 13 spesies jenis ikan yang terdiri dari 42 individu ikan yang tertangkap saat penelitian.
\end{abstract}

\section{Kata Kunci : Kualitas Air dan Keanekaragaman jenis ikan di Lubuk Manik Kecamatan Rantau Pandan.}


SEMAH : Journal Pengelolaan Sumberdaya Perairan VOL. 3 No. 1

April 2019

\section{PENDAHULUAN}

Provinsi Jambi memilki perairan umum sekitar 115.500 Ha yang terdiri dari perairan sungai $48.000 \mathrm{Ha}$, danau $5000 \mathrm{Ha}$, rawa dan genangan air $61.900 \mathrm{Ha}$. Dengan potensi lestari perikanan perairan umumnya 35.500 ton per tahun dan tingkat pemamfaatan sudah mencapai 7.798,9 ton/tahun (Dinas Kelautan dan Perikanan Provinsi Jambi, 2015).

Kabupaten Bungo merupakan salah satu Kabupaten di Provinsi Jambi mempunyai luas Perairan umum seluas 6.907 Ha yang terdiri dari perairan sungai, rawa, danau, bendungan dan genangan air lannya. Beberapa sungai utama yang ada di Kabupaten Bungo antara lain : Sungai Batang Jujuhan dengan panjang $\quad \pm 153$ km, Sungai Batang Tebo dengan panjang \pm 80 km, Sungai Batang Bungo dengan panjang $\pm 50 \mathrm{~km}$, Sungai Batang Senamat dengan panjang $\pm 90 \mathrm{~km}$, dan Sungai Batang Pelepat dengan panjang $\pm 80 \mathrm{~km}$ (Dinas Peternakan dan Perikanan Kabupaten Bungo, 2015).

Suaka Perikanan (Reservat) Lubuk Manik adalah salah satu suaka perikanan tertua di Propinsi Jambi yang berada di Kababupaten Bungo tepatnya di Kecamatan Rantau Pandan yang juga merupakan bagian dari hulu Sungai Batang
ojs.umb-bungo.ac.id/index-php/SEMAHJPSP

ISSN : 2580-0736

Bungo dengan luas $4.500 \quad \mathrm{M}^{2}$. Suaka perikanan ini didirikan pada tahun 1990, diresmikan oleh Pemerintah Pusat pada tahun 1994 dan kembali dikukuhkan zonasinya oleh Pemerintah Kabupaten Bungo pada tahun 2006 (Dinas Peternakan dan Perikanan Bungo, 2006).

Reservat atau dengan kata lain suaka perikanan merupakan suatu ekosistem perairan yang memiliki daerah yang terbatas, di mana semua kegiatan penangkapan biota perairan dengan cara apapun, kapanpun dan oleh siapapun, dilarang, karena memiliki fungsi sebagai tempat pelestarian ikan-ikan endemik yang langka (atau hampir punah) dan beberapa spesies yang dilindungi keberadaannya.

Reservat secara khusus merupakan tempat penelitian biota endemik yang langka, dan beberapa spesies yang hampir punah untuk dikembangbiakan dengan meneliti cara makan, beradaptasi, pemijahan, dan pakan alami dari larva sampai menjadi dewasa, agar bisa dikembalikan kembali ke habitat semula untuk menjaga keseimbangan ekosistem.

Berdasarkan observasi lapangan, Suaka Perikanan Lubuk Manik belum banyak memiliki data dasar secara ilmiah di berbagai bidang, salah satunya yaitu tentang kualitas perairan ditinjau 
SEMAH : Journal Pengelolaan Sumberdaya Perairan VOL. 3 No. 1

April 2019

dari parameter fisika dan kimia serta status mutu air peruntukan daerah suaka perikanan seperti yang telah ditetapkan di dalam PP RI No. 82 tahun 2001 tentang Pengelolaan Kualitas Air dan Pengendaliaan Pencemaran Air serta PP RI No. 60 tahun 2007 tentang Konservasi Sumber Daya Ikan. Hal ini disebabkan oleh beberapa kendala mulai dari jauhnya lokasi daerah konservasi perikanan, sampai kurangnya financial dan sumberdaya manusia dalam kegiatan penelitian.

Oleh karena itulah penulis tertarik untuk membantu memantau kondisi kualitas perairan Suaka Perikanan (Reservat) Lubuk Manik ditinjau dari parameter fisika dan kimia berdasarkan Baku Mutu Air Kelas III peruntukan kegiatan perikanan sesuai PP RI No. 82 tahun 2001

Penelitian ini dilaksanakan di kawasan Suaka Perikanan Lubuk Manik, sungai Batang Bungo, Kecamatan Rantau Pandan, Kabupaten Bungo. Waktu penelitian dilaksanakan selama 4 (empat) bulan, tahap persiapan dan survei dilakukan bulan Maret - April dan dilanjutkan dengan pengolahan data bulan Mei - Juni 2018.
ojs.umb-bungo.ac.id/index-php/SEMAHJPSP

ISSN : 2580-0736

\section{METODOLOGI PENELITIAN}

Berdasarkan tujuan penelitian yang akan dicapai dan metode penelitian yang akan digunakan yaitu untuk data primer dengan cara observasi langsung dilapangan dan melakukan wawancara kepada nelayan setempat sebagai sumber informasi langsung yang ada dilapangan, serta data sekunder diperoleh dari dinas dan instansi terkait, Penelitian ini bersifat deskriptif kuantitatif, yaitu untuk memberikan gambaran dan penjelasan secara sistematis, faktual, dan akurat mengenai fakta-fakta dan gejala yang ada di lokasi penelitian.

Eksperimen, yaitu melakukan survei, pengambilan data dan pengamatan langsung di lapangan serta hasil pengambilan sampel dianalisis di laboratorium.

Dalam penentuan stasiun penelitian ini digunakan Metode Purposive Sampling yaitu penentuan stasiun penelitian dilakukan berdasarkan tujuan dengan memperhatikan berbagai pertimbangan kondisi dan keadaan tempat penelitian atau Karakteristik seperti kondisi dominan aktivitas masyarakat di perairan lubuk manik dan lain-lain.

Populasi yang diamati sebagai objek penelitian adalah Suaka Perikanan/Reservat Lubuk Manik yang terdapat di Kecamatan Rantau Pandan 
SEMAH : Journal Pengelolaan Sumberdaya Perairan VOL. 3 No. 1

April 2019

Kabupaten Bungo, sedangkan sampel penelitian sebagai fokus kajian adalah :

a. Kualitas Biofisik Perairan di (Reservat) yaitu pada zona penyangga hulu, zona inti dan zona penyangga hilir.

b. Keanekaragaman Jenis Ikan yaitu hasil tangkapan yang dilakukan oleh nelayan pada zona ekonomi suaka perikanan (Reservat).

Analisis Data

Untuk menganalisis data yang diperoleh dari dilapangan digunakan beberapa metoda analisis. Metoda analisis tersebut adalah sebagai berikut:

- Analisis Kualitas Perairan

Untuk analisis kualitas perairan, hasil pengukuran karakteristik kualitas air (fisika dan kimia) yang diperoleh dibandingkan dengan standar baku mutu air berdasarkan Peraturan Pemerintah Nomor 82 Tahun 2001 tentang Pengelolaan Kualitas Air dan Pengendalian Pencemaran Air sesuai dengan peruntukkan kegiatan perikanan dalam klasifikasi Kelas III.

- Identifikasi Ikan

Identifikasi ikan dilakukan di Laboratorium Biologi Universitas Muara Bungo dengan mengamati ciri-ciri morfologi pada ikan yang tertangkap oleh nelayan.
ojs.umb-bungo.ac.id/index-php/SEMAHJPSP

ISSN : 2580-0736

Keanekaragaman jenis ikan di identifikasikan dengan menggunakan metode yang dinyatakan oleh Kottelat et al dalam Krismono, et al. (2009) yaitu memakai buku identifikasi ikan. Selanjutnya setiap spesies ikan dikelompokan berdasarkan ordo, famili, genus, spesies dan reproduksi ikan diperoleh dari percobaan penangkapan dengan menggunakan alat tangkap jala tebar atau pancing.

\section{HASIL PENELITIAN}

\section{Kualitas Perairan}

Hasil pengamatan Biofisik perairan (parameter fisika dan kimia) perairan suaka perikanan /Reservat Lubuk Manik di ambil pada musim kemarau yaitu pengambilan pertama pada tanggal 13 Maret 2018, pengambilan kedua pada tanggal 04 April 2018 dan pengambilan ketiga pada tanggal 28 April 2018.

a. Parameter Fisika Perairan

Parameter fisika perairan yang di amati pada penelitian ini adalah Suhu, Kecerahan, Total Dissolved Solids (TDS) dan Total Suspensi Solid (TSS), seperti pada Tabel 3.

Tabel 3. Nilai rentang parameter fisika perairan yang diukur pada masing masing stasiun penelitain. 
April 2019

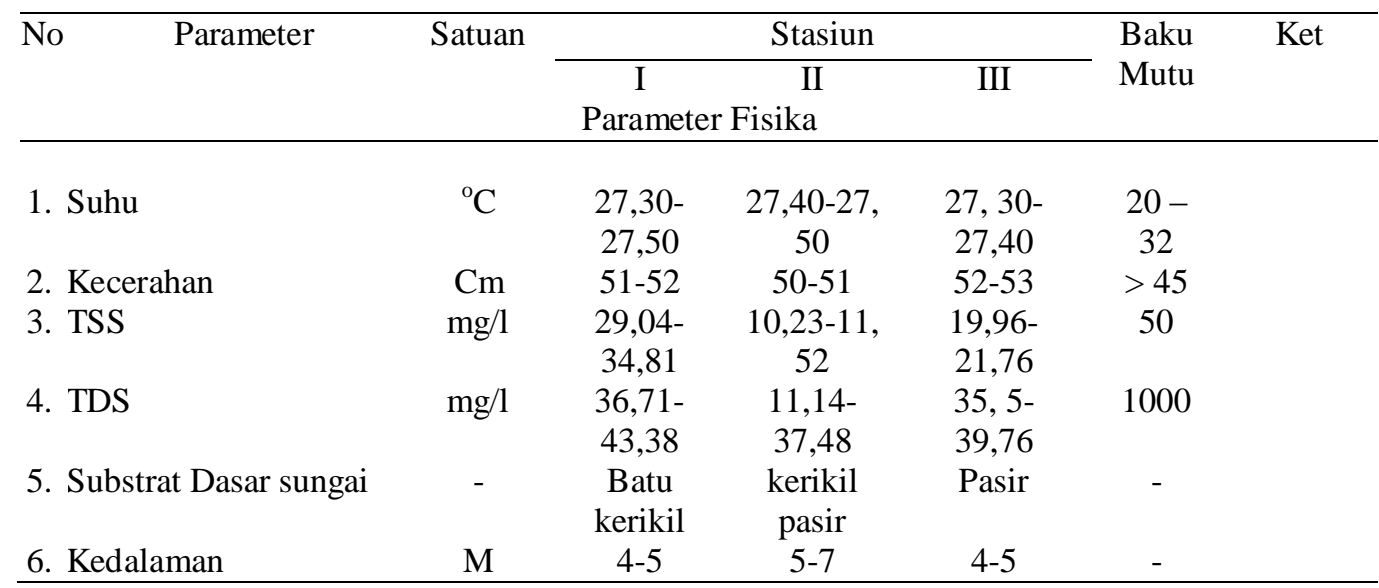

b. Parameter Kimia Perairan

Parameter kimia perairan yaitu $\mathrm{pH}, \mathrm{DO}$, $\mathrm{BOD}_{5}, \mathrm{COD}$, Nitrit, Phospat dan Amoniak yang diambil pada masing-masing stasiun penelitian dapat dilihat pada Tabel 4 .
Tabel 4. Nilai Rentang Parameter Kimia Perairan yang Diukur Pada Masing-Masing Stasiun Penelitian.

Sumber : Data primer yang diolah Mei 2018

\begin{tabular}{|c|c|c|c|c|c|}
\hline \multirow[t]{3}{*}{ Parameter } & \multirow[t]{3}{*}{ Satuan } & \multicolumn{3}{|c|}{ Stasiun } & \multirow{3}{*}{$\begin{array}{l}\text { Baku } \\
\text { Mutu }\end{array}$} \\
\hline & & I & II & III & \\
\hline & & \multicolumn{3}{|c|}{ Parameter Kimia } & \\
\hline 1. $\mathrm{pH}$ & Unit & $7,10-7,16$ & $7,30-7,82$ & $7,30-7,60$ & 6-9 \\
\hline 2. DO & $\mathrm{mg} / \mathrm{l}$ & $7,28-7,52$ & $6,68-6,86$ & $6,16-6,60$ & 4 \\
\hline 3. $\mathrm{BOD}_{5}$ & $\mathrm{mg} / \mathrm{L}$ & $1,39-1,56$ & $0,70-0,79$ & $0,94-1,11$ & 3 \\
\hline 4. COD & $\mathrm{mg} / \mathrm{L}$ & $20,69-22,52$ & $6,08-10,47$ & $12,40-18,21$ & 25 \\
\hline 5. vitrit $\left(\mathrm{N}-\mathrm{NO}_{2}\right)$ & $\mathrm{mg} / \mathrm{L}$ & $0,081-0,095$ & $0,040-0,044$ & $0,087-0,092$ & 0,06 \\
\hline 6. Phospat $\left(\mathrm{P}-\mathrm{PO}_{4}\right)$ & $\mathrm{mg} / \mathrm{L}$ & $0,06-0,08$ & $0,01-0,09$ & $0,10-0,13$ & 0,2 \\
\hline 7. Amoniak $\left(\mathrm{N}-\mathrm{NH}_{4}\right)$ & $\mathrm{mg} / \mathrm{L}$ & $0,10-0,15$ & $0,10-0,12$ & $0,12-0,20$ & 1 \\
\hline
\end{tabular}

Parameter kimia perairan stasiun II seperti $\mathrm{pH}$,sebesar 7,30 - 7,82 bila hasil pengukuran tersebut dibandingkan dengan baku mutu air untuk peruntukan kelas III Peraturan Pemerintah No.82 Tahun 2001 sebesar 6-9, kisaran $\mathrm{pH}$ pada stasiun II masih di antara nilai ambang batas mutu air.

\section{Keanekaragaman Jenis Ikan}

Hasil penelitian menunjukkan bahwa jenis ikan yang ditemukan dari masing-masing stasiun penelitian ditemukan 18 Spesies, 18 Genus dari 8 Famili dan 4 Ordo.

\section{Nilai Keanekaragaman Jenis Ikan (Hi)}

Menurut Soegianto dalam

Muhammad J, Emiyarti dan Syamsul K, 
2013, bahwa indeks keanekaragaman jenis (Hi) adalah indeks yang menunjukkan banyak tidaknya jenis dan individu yang ditemukan pada suatu perairan.
Sumber : Data primer diambil bulan Juli 2018

Berdasarkan hasil perhitungan nilai indeks keanekaragaman pada Tabel 5 tersebut di atas, bahwa kisaran nilai indeks keanekaragaman jenis ikan

\begin{tabular}{ccccc}
\hline No & Tanggal & \multicolumn{3}{c}{ Nilai Indeks Keanekaragaman (Hi) } \\
\hline 1 & $12-20$ & ST I & ST II & ST III \\
& Juli & Lubuk Manik & Lubuk Manik & Lubuk Manik \\
& & & \\
& 2018 & & & 1,1394 \\
\hline & & 1,5254 & 1,6565 & \\
\hline
\end{tabular}

Selanjutnya menurut Fachrul dalam Muhammad J, Emiyarti dan Syamsul K, 2013, menjelaskan bahawa indeks keanekaragaman (indeks of diversity) berguna dalam mempelajari gangguan faktor-faktor lingkungan (abiotik) terhadap suatu komunitas atau untuk mengetahui suksesi atau stabilitas suatu komunitas. Tujuan utama teori informasi Shannon-Wienner adalah untuk mengukur tingkat keteraturan dan ketidakteraturan dalam suatu sistem.

Nilai indeks Keanekaragaman Jenis Ikan (Hi) yang tertangkap selama penelitian di kawasan Suaka Perikanan (Reservat) Lubuk Manik Kecamatan Rantau Pandan berdasarkan Indeks Shannon dapat dilihat pada Tabel 5.

Tabel 5. Nilai Keanekaragaman Jenis Ikan (Hi).
(Hi) yang tertangkap selama penelitian di kawasan suaka perikanan (Reservat) Lubuk Manik Kecamatan Rantau Pandan dimana indeks tertinggi ditemui pada Stasiun II dengan nilai indeks 1.6565 , terdapat 18 spesies jenis ikan yang terdiri dari 57 individu ikan yang tertangkap saat penelitian, stasiun II ini berada pada Zona Inti yang merupakan kawasan tidak boleh dilakukan penangkapan sepanjang tahun terkecuali untuk kepentingan khusus seperti riset ilmiah. Luas area $4500 \mathrm{M}^{2}$. Lebih tingginya nilai indeks keanekaragaman (Hi) Stasiun II dibanding stasiun lain (Stasiun 1 dan III) di karenakan lokasi stasiun II merupakan Zona inti dari kawasan suaka perikanan Reservat Lubuk 
SEMAH : Journal Pengelolaan Sumberdaya Perairan VOL. 3 No. 1

April 2019

Manik yang tidak boleh diganggu sepanjang tahun, maka ikan-ikan lebih cenderung berdiam dan nyaman di tempat yang tidak diganggu oleh manusia, jika ditinjau dari parameter fisika perairan stasiun II merupakan kawasan dengan substrat dasar sungai berbatu kerikil dan berpasir dengan kedalaman $4-7$ m. merupakan tempat paling dalam dari stasiun lainnya. hal ini selaras dengan pernyataan Menurut Utomo et el(2001) salah satu kriteria suaka perikanan kedalaman air yang cukup adalah ( minimal $2 \mathrm{~m}$ ) sehingga tidak mengalami kekeringan pada musim kemarau.

Sedangkan keanekaragaman jenis ikan (Hi) terendah terdapat di stasiun III dengan nilai indeks 1,1394, terdapat 13 spesies jenis ikan yang terdiri dari 42 individu ikan yang tertangkap saat penelitian, stasiun III ini berada pada zona pemanfaatan terletak di bagian hilir zona inti, zona ini berfungsi sebagai sumber kawasan yang diperbolehkan untuk menangkap ikan bagi keperluan mata pencaharian masyarakat sekitarnya. Sehingga terdapat aktivitas penangkapan ikan secara berkelanjutan, yang menyebabkan ikan-ikan merasa terganggu, yang menyebabkan
ojs.umb-bungo.ac.id/index-php/SEMAHJPSP

ISSN : 2580-0736

menurunnya keanekaragaman jenis ikan di zona ini.

\section{Kepadatan Populasi, Kepadatan Relatif an Frekuensi Kehadiran}

Berdasarkan hasil sampel ikan yang tertangkap Tabel 5 . dapat disajikan pada rekap hasil perhitungan Kepadatan Populasi, Kepadatan Relatif, dan Frekuensi Kehadiran pada Tabel 6.

Tabel 6. Rekap Hasil Perhitungan Kepadatan Populasi, Kepadatan Relatif, dan Frekuensi Kehadiran.

Dari Tabel 6 di diatas dapat dilihat bahwa kepadatan Populasi (KP), Kepadatan Relatif (KR\%), dan Frekuensi Kehadiran (FK). Kepadan Populasi (KP) tertinggi ditemukan 3 Jenis Ikan diantaranya adalah : Puntius schwanefeldi (Kefiat) sebesar 0,005 (individu)/ $\mathrm{m}^{2}$, Macrones nemurus C.V (Baung) sebesar 0,004 (individu) $/ \mathrm{m}^{2}$, kemudian disusul oleh jenis Ikan Ophiocephalus striatus Bl (Baung) sebesar 0,003 (individu) Hal ini di duga bahwa ikan Kefiat, Baung,dan Baung akar, pada umumnya ikan perairan umum,yang hidup di sungai kecil hingga besar dengan arus yang deras hingga senang. di samping kualitas air yang mendukung untuk 


\begin{tabular}{|c|c|c|c|c|}
\hline \multirow{2}{*}{ No } & \multirow{2}{*}{ Spesies } & \multirow{2}{*}{$\mathrm{KP}$} & \multirow{2}{*}{$\frac{\mathrm{KR}}{\%}$} & \multirow{2}{*}{$\frac{\mathrm{FK}}{\%}$} \\
\hline & & & & \\
\hline 1 & Puntius schwanefeldi (Kefiat) & 0.005 & 13.69 & 100 \\
\hline 2 & Neolissochilus sumatranus (Simancung) & 0.003 & 8.21 & 100 \\
\hline 3 & Osteochilus hasseti(C.V) (Palau) & 0.001 & 3.43 & 66 \\
\hline 4 & Osteochilus hasselti (CV) (Nilem) & 0.001 & 2.73 & 66 \\
\hline 5 & Barbonymus gonionotus (Tawes) & 0.001 & 3.43 & 33 \\
\hline 6 & Labiobarbus fasciatus (Masik) & 0.001 & 4.10 & 66 \\
\hline 7 & Dangila cuvieri c.v (Umbu-Umbu) & 0.001 & 3.43 & 100 \\
\hline 8 & Hampala. (Hampala) & 0.001 & 3.43 & 66 \\
\hline 9 & Rasbora argyrotaenia (Seluang) & 0.003 & 8.90 & 100 \\
\hline 10 & Cryptopterus limpok (Blkr) (Lais) & 0.001 & 3.43 & 100 \\
\hline 11 & Osphronemus guramilac (Gurami) & 0.001 & 3.43 & 100 \\
\hline 12 & Leiocassic (Kepuntin) & 0.001 & 4.10 & 100 \\
\hline 13 & Macrones nemurus C.V (Baung) & 0.004 & 13.01 & 100 \\
\hline 14 & Trichogaster trichopterus (Sepat) & 0.001 & 3.43 & 100 \\
\hline 15 & Helostoma temminckii (Tembakang) & 0.002 & 4.80 & 100 \\
\hline 16 & Ophiocephalus striatus Bl (Baung) & 0.003 & 10.27 & 100 \\
\hline 17 & Mastacembelus maculatus.c.v (Tilan) & 0.002 & 4.80 & 100 \\
\hline 18 & Oxyeleotris marmorata (Betutu) & 0.0005 & 1.36 & 66 \\
\hline & Jumlah & 0.0115 & 100 & \\
\hline
\end{tabular}

habitat hidupnya. Sebaliknya untuk Kepadatan Populasi (KP) terendah terdapat pada beberapa jenis yaitu ikan Oxyeleotris marmorata (Betutu) dan Osteochilus hasselti (CV) (Nilem). Rendahnya Kepadatan Populasi (KP) kedua jenis ikan tersebut di duga karena, lokasi penelitian tidak sesuai dengan habitat hidupnya atau ketidak mampuannya dalam beradaptasi dengan lingkungan dengan substrat dasar sungai berbatu,batuan kerikil dan berpasir dengan arus aliran sungai yang cukup deras.

Untuk Kepadatan Relatif (KR\%) paling tinggi terdapat pada ikan Puntius schwanefeldi (Kefiat) sebesar $13.69 \%$. Sedangkan Kepadatan Relatif (KR \%) terendah ditemukan pada ikan Oxyeleotris marmorata (Betutu) sebesar $1.36 \%$.

Selanjutnya untuk Frekuensi Kehadiran (FK \%) tertinggi atau Absolut di temukan pada 18 jenis ikan yaitu : ikan Puntius schwanefeldi 
SEMAH : Journal Pengelolaan Sumberdaya Perairan VOL. 3 No. 1

April 2019

(Kefiat) (100\%), Neolissochilus sumatranus (Simancung) (100\%),

Osteochilus hasseti(C.V) (Palau) (66\%),Osteochilus hasselti (CV) (Nilem) (66\%), Barbonymus gonionotus (Tawes) (33\%), Labiobarbus fasciatus (Masik) (66\%), Dangila cuvieri c.v (Umbu-Umbu) (100\%), Hampala. (Hampala) (66\%), Rasbora argyrotaenia (Seluang) (100\%), Cryptopterus limpok (Blkr) (Lais) $\quad(100 \%)$,Osphronemus guramilac (Gurami) (100\%)., Leiocassic (Kepuntin) (100\%),Macrones nemurus C.V (Baung) (100 \%), Trichogaster trichopterus (Sepat) (100\%),Helostoma temminckii (Tembakang) (100\%),Ophiocephalus striatus $\quad B l \quad$ (Baung)(100\%), Mastacembelus maculatus.c.v (Tilan) (100\%), Oxyeleotris marmorata (Betutu). (66\%),

Frekuensi Kehadiran (FK\%)

Tertinggi ditemukan pada jenis ikan Puntius schwanefeldi (Kefiat) (100\%),Ophiocephalus striatus Bl (Baung)(100\%), Macrones nemurus C.V (Baung) (100\%), dan terendah di temukan pada jenis ikan yaitu, Barbonymus gonionotus (Tawes) $(33 \%)$.
ojs.umb-bungo.ac.id/index-php/SEMAHJPSP

ISSN : 2580-0736

\section{KESIMPULAN}

Dari hasil penelitian yang telah dilakukan maka dapat diambil kesimpulan sebagai berikut :

1. Kondisi kualitas perairan Suaka Perikanan Lubuk Manik Rantau Pandan ditinjau dari parameter fisika dan kimia perairan masih dalam kisaran normal dan tidak ada yang melampaui ambang batas Baku Mutu Air Kelas III peruntukan kegiatan perikanan yang telah tertuang dalam PP RI No. 82 Tahun 20011.

2. Jenis ikan yang ditemukan dari masing-masing stasiun penelitian ditemukan 18 Spesies, 18 Genus dari 8 Famili dan 4 Ordo. Jenis Ikan yang ditemui di di Suaka Perikanan/Reservat Lubuk Manik

\section{DAFTAR PUSTAKA}

Budiyono, 2011, Analisis Pengaruh Penambangan Emas dan Pasir Terhadap Kualitas Air dan Keanekaragaman Jenis Ikan di Sungai Batang Bungo Kabupaten Bungo. Tensis Pasca Sarjana Universitas Bung Hatta.

Dinas Kelautan dan 57 ikanan Propinsi Jambi, 2, aporan Tahunan Kelautan dan perikanan propinsi jambi, Dinas kelautan dan perikanan Propinsi Jambi. 
Dinas Peternakan dan perikanan kabupaten Bungo, 2015. Laporan Tahunan Statistik Perikanan Tangkap Dinas Peternakan dan Perikanan Kabupaten Bungo, Muara Bungo.

Djuhanda, T. 1981. Dunia Ikan. Bandung: Armico

Kent, G. C. 1987 Comparative Anatomy of The Vertebrates. St. Louis-Toronto-Santa Clara: Time Mirror/Mosby Colloge Publishing.

Koesbiono. 1989. Dasar-Dasar Ekologi Umum. IPB, Bogor.

Kottelat, M; A. J. Whitten; S. N. Kartikasari \& S. Wirjoatmojo. 1993. Freshwater of Western Indonesia and Sulawesi. London: Periplus Edition.

Kottelat et al 1993. Indonesia merupakan Negara kepulauan dengan tingkat biodiversitas tertinggi setelah Brazil

Krebs C.J. 1971. Ecology, The Experimental Analysis of Distribusi and Abundance. Harper and Rows Publiser.

Mochamad Idrawan, 2007: 16-18. Tingkatan Keanekaragaman Hayati. 